EPJ Web of Conferences 106, 03010 (2016)

DOI: $10.1051 /$ epjconf/201610603010

(C) Owned by the authors, published by EDP Sciences, 2016

\title{
Validating the Serpent Model of FiR 1 Triga Mk-II Reactor by Means of Reactor Dosimetry
}

\author{
Tuomas Viitanen and Jaakko Leppänen
}

VTT Technical Research Centre of Finland, PL 1000, 02044 VTT, Finland

\begin{abstract}
A model of the FiR 1 Triga Mk-II reactor has been previously generated for the Serpent Monte Carlo reactor physics and burnup calculation code. In the current article, this model is validated by comparing the predicted reaction rates of nickel and manganese at 9 different positions in the reactor to measurements. In addition, track-length estimators are implemented in Serpent 2.1.18 to increase its performance in dosimetry calculations. The usage of the track-length estimators is found to decrease the reaction rate calculation times by a factor of 7-8 compared to the standard estimator type in Serpent, the collision estimators. The differences in the reaction rates between the calculation and the measurement are below $20 \%$.
\end{abstract}

\section{Introduction}

A model of the FiR 1 Triga Mk-II reactor has been previously developed at VTT for the Serpent Monte Carlo reactor physics code $[1,2]$. In the past, the model has been used to calculate the rod-wise nuclide inventories and burnups. However, the calculation model has only been validated rather coarsely by checking that the multiplication factor of the system remains within reasonable limits throughout the operational history from 1962 to present and, additionally, by comparing the inventories to ORIGEN calculations [3]. As the current reactor physical model involves numerous simplifications and possibly also coarse errors, it would be beneficial to proceed with the validation of the model by comparing its predictions to other easily measurable data.

In the current work, the fast and thermal neutron flux distributions of FiR 1 are first measured in the radial and the azimuthal direction by irradiating neutron dosimeters in the central thimble and in the Lazy Susan irradiation ring. The measured reaction rates are compared to Serpent calculations. The current study has two primary functions: First, it validates the FiR 1 Serpent model against experimental data and, second, it familiarizes a new expert with the field of reactor dosimetry by providing hand-on experience on the tools and practices of neutron dosimetry.

This is an Open Access article distributed under the terms of the Creative Commons Attribution License 2.0, which permits unrestricted use, distribution, and reproduction in any medium, provided the original work is properly cited. 


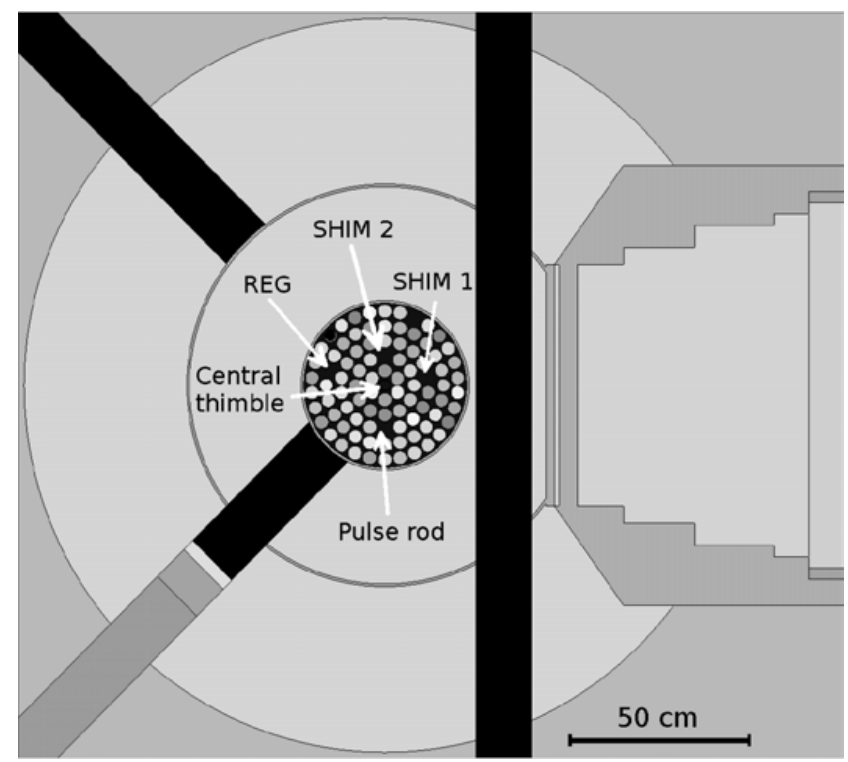

Figure 1. Serpent geometry plot of the FiR 1 model: top view.

\section{Methods}

\subsection{FiR 1 Reactor}

FiR 1 is the first nuclear reactor in Finland, located in Otaniemi, Espoo and operated by the VTT Technical Research Centre of Finland. It is a pool-type Triga Mk-II research reactor with $250 \mathrm{~kW}$ thermal power. The reactor started operation in 1962 with $100 \mathrm{~kW}$ power and the power was upgraded to $250 \mathrm{~kW}$ in 1967 . The reactor experienced major changes in the mid-1990s, when the graphite of the thermal column was replaced with FLUENTAL moderator $\left(30 \% \mathrm{Al}, 69 \% \mathrm{AlF}_{3} 1 \% \mathrm{LiF}\right)$, developed at VTT, to provide an optimal epithermal flux for Boron Neutron Capture Therapy (BNCT) treatments [4]. At the same time the loading of the reactor was changed such that the fuel rods closest to the BNCT facility were replaced with stainless steel cladded rods with $12 \%$ uranium content, resulting in a tilted flux distribution in the reactor and a maximal epithermal flux at the BNCT facility. The total energy production during 52 years of operation is about $500 \mathrm{MWd}$.

\subsection{Calculation Model of FiR 1}

Serpent is a Monte Carlo reactor physics and burnup calculation code that is developed at the VTT Technical Research Centre of Finland. The code is distributed via OECD/NEA Databank and RSICC (USA) and has currently users in 103 universities and research organizations around the world. The calculations of the current study are made using code version 2, which is currently in beta-testing phase $[1,2]$.

The Serpent model of the FiR 1 reactor is rather detailed near the reactor core, and the level of detail is somewhat decreased further away from the core. The model includes, for instance, one tangential and two radial beam tubes and a detailed model of the thermal column that was later on converted to an epithermal neutron source. The calculation model is illustrated in the geometry plots provided in Figs. 1 and 2. The fuel compositions in the model are based on an extensive burnup calculation that was 


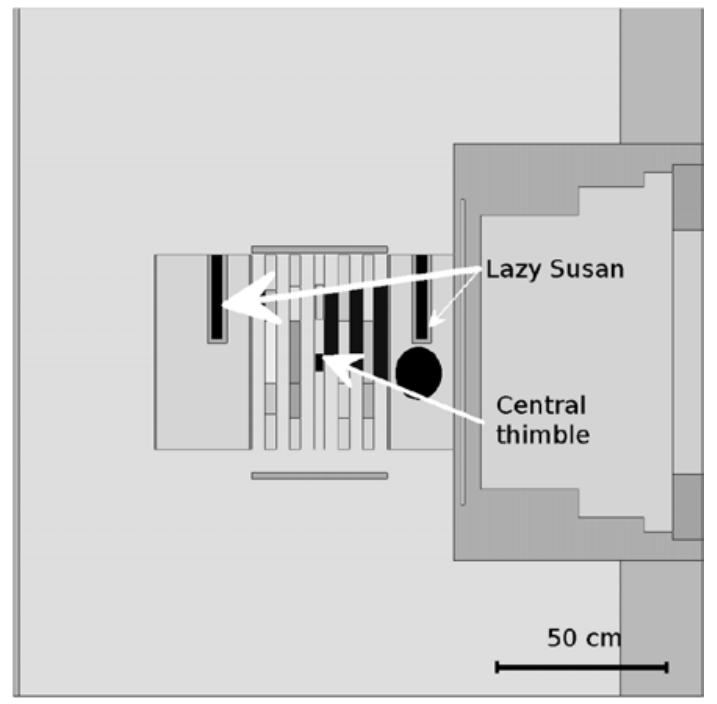

Figure 2. Serpent geometry plot of the FiR 1 model: side view.

performed in 2011 using Serpent 1. In this calculation all the changes in the fuel loading from 1962 to 2010 were taken into account and the power history was based on yearly total power productions.

The model used in the current work and in the burnup calculation involves at least three significant limitations. First, all of the fuel material is assumed to be at $400 \mathrm{~K}$ temperature. Hence, the strong fuel temperature feedback specific to the $\mathrm{ZrH}$ fuel of the Triga reactors is not correctly modelled. Since the temperature feedback tends to flatten the radial power distribution in the reactor, the lack of this feedback effect may introduce bias in the spatial distribution of the neutron flux. Second, each fuel rod is divided in only three material regions axially, so the burnup distributions are modelled only very coarsely. Third, the fuel inventories correspond to the situation in the end of the year 2010 followed by several months of cooling-down. Thus, the inventories are not quite up-to-date and the effect of relatively short-lived reactor poisons on the distribution of the neutron flux is not taken into account.

In addition to these inaccuracies, the rod-wise burnups and nuclide inventories of the current reactor model are affected by the uncertainties in the nuclear data. Due to the complexity of the problem, the overall uncertainty of the burnup calculation is very hard to determine quantitatively, but since the calculation involved the most accurate available history data of the reactor, recent data libraries [5] and state-of-the-art burnup calculation methodology [1], the rod-wise burnups and inventories of important long-lived nuclides are expected to be at least in the correct ballpark despite all the sources of uncertainty.

\subsection{Implementation of Track-length Estimators}

In Serpent the reaction rates are normally calculated using collision estimators, which are scored at collision sites of the neutron transport process. Reason for this is that the tracking algorithm of Serpent combines surface-tracking with Woodcock Delta-tracking. Since the surface crossings are not recorded in the Delta-tracking mode, the track-lengths cannot be easily resolved and, consequently, usage of track-length estimators as the standard means of calculating reaction rates would be rather cumbersome. Usage of collision estimators also provides for modelling of heterogeneous material regions within the system, which is very beneficial when modelling systems with thermal hydraulics feedback. 
The collision estimators work well-enough in most reactor-physical applications, but when examining reaction rates in regions with low neutron flux, for example far from the active reactor core, the collision estimators may be unfeasibly inefficient. In other words, gathering enough statistics may simply require more neutron histories than the user of the code can afford to calculate.

To increase the efficiency of reaction rate estimators in problematic regions, a special track-length detector ("tally") type was implemented in Serpent 2.1.18. Because of the Delta-tracking approach used in Serpent, each sampled path length may penetrate several surfaces. Consequently, the surface crossings along the path need to be determined by analysing the neutron tracks preceding each collision point. With the new track-length detector, an algorithm seeks the surface crossings along each neutron path, and in case the neutron is found to travel within a surface outlining a detector, the track-length inside this surface is calculated and stored. By multiplying the track-lengths with values of response functions, it is possible to calculate integral quantities like reaction rates within the surface. The only practical difference to the traditional way of implementing track-length estimators in Monte Carlo codes is in the retrospective determination of the track-lengths: normally, i.e. when using surface-tracking only, the track-lengths are (at least semi-)automatically obtained during the transport process.

The additional analysis of neutron tracks is expected to somewhat increase the total calculation times, but this overhead should be well-compensated by the generally higher efficiency of the tracklength estimators compared to collision estimators.

\section{Results}

All of the calculations were performed using JEFF-3.1.1 based cross section data for the transport and IRDF2002 cross sections for the reaction rates of the dosimeters [5, 6]. The calculations were done using 12 OpenMP threads on an Intel Xeon workstation with $12 \mathrm{CPUs}$ running at $3.47 \mathrm{GHz}$. 400 million active neutron histories were simulated in each calculation.

The irradiation of the neutron dosimeters is first described in Sect. 3.1, the performance of the track-length estimators is demonstrated in Sect. 3.2 and the measured reaction rates are compared to calculations in Sect. 3.3.

\subsection{Irradiation of Neutron Dosimeters}

Nickel and manganese were chosen as the neutron dosimeter materials to measure the fast and thermal flux distributions in the reactor, respectively. The nickel samples were short pieces of $99.999 \%$ pure Nickel wire, and the manganese samples were small $\mathrm{Mn}$-Al discs with $0.1 \% \mathrm{Mn}$ content.

To measure both the radial and azimuthal flux distributions in the reactor, altogether $9+9(\mathrm{Ni}+\mathrm{Mn})$ samples were irradiated. The $\mathrm{Ni}$ and $\mathrm{Mn}$ dosimeters were irradiated separately. In both of the irradiations, one sample was placed in the central thimble of the reactor (CT) and other 8 samples were located in positions $1,6, \ldots, 36$ of the Lazy Susan irradiation ring (LS1...36). For Ni samples the irradiation time was $303+/-1 \mathrm{~min}$ at full power, followed by one week of cooling-down before measurement due to ${ }^{58 \mathrm{~m}} \mathrm{Co}$ decay $\left(\mathrm{T}_{1 / 2}=9.04 \mathrm{~h}\right)$. The Mn samples were irradiated at full power for $21.5+/-0.5 \mathrm{~min}$. The samples were cooled down 18 hours prior to measurement for the activity to become optimal for the gamma spectrometry equipment of VTT.

In both of the irradiations, the pulse and the SHIM 1 control rods were fully withdrawn and the SHIM 2 control rod was at $50 \%$. In the Ni irradiation the position of the REG control rod varied between $77.4 \%$ and $91 \%$ (withdrawn), and for the Mn irradiation the REG rod was at $68.8 \%$ all the time. The differences in the REG rod position at full-power are mainly due to the different operational histories of the reactor prior to the irradiations and the different durations of the irradiations.

The masses, specific activities and reaction rates calculated using the FitzPeaks gamma analysis software are provided in Table 1 . In the current work, reactions ${ }^{55} \mathrm{Mn}(\mathrm{n}, \mathrm{r}){ }^{56} \mathrm{Mn}$ and ${ }^{58} \mathrm{Ni}(\mathrm{n}, \mathrm{p}){ }^{58} \mathrm{Co}$ are 


\section{$15^{\text {th }}$ ISRD}

Table 1. Results of the dosimetry irradiation: measured specific activities and reaction rates.

\begin{tabular}{|c|c|c|c|c|c|}
\hline ID & Mass & Activity & $\begin{array}{l}\text { Error in } \\
\text { activity }\end{array}$ & $\begin{array}{c}\text { Reaction } \\
\text { rate }\end{array}$ & $\begin{array}{c}\text { Error in reaction } \\
\text { rate }\end{array}$ \\
\hline & $\mathrm{g}$ & $\mathrm{Bq} /$ target & $\%$ & $1 / \mathrm{s}$ & $\%$ \\
\hline $\mathrm{Mn} \_\mathrm{CT}$ & 0.05680 & 7.47E-12 & 1.3 & $8.13 \mathrm{E}-011$ & 2.7 \\
\hline Mn_LS1 & 0.05622 & $1.39 \mathrm{E}-12$ & 1.6 & $1.51 \mathrm{E}-011$ & 2.8 \\
\hline Mn_LS6 & 0.05736 & $1.44 \mathrm{E}-12$ & 1.7 & $1.38 \mathrm{E}-011$ & 2.9 \\
\hline Mn_LS11 & 0.05816 & $1.35 \mathrm{E}-12$ & 1.7 & $1.47 \mathrm{E}-011$ & 2.9 \\
\hline Mn_LS16 & 0.05863 & $1.36 \mathrm{E}-12$ & 1.7 & $1.31 \mathrm{E}-011$ & 2.9 \\
\hline Mn_LS21 & 0.05719 & $1.46 \mathrm{E}-12$ & 1.7 & $1.59 \mathrm{E}-011$ & 2.9 \\
\hline Mn_LS26 & 0.05811 & $1.37 \mathrm{E}-12$ & 1.8 & $1.49 \mathrm{E}-011$ & 2.9 \\
\hline Mn_LS31 & 0.05639 & $1.02 \mathrm{E}-12$ & 2.1 & $1.10 \mathrm{E}-011$ & 3.1 \\
\hline Mn_LS36 & 0.05772 & $1.14 \mathrm{E}-12$ & 2.1 & $1.24 \mathrm{E}-011$ & 3.1 \\
\hline Ni_CT & 0.01142 & $9.84 \mathrm{E}-16$ & 1.2 & $4.78 \mathrm{E}-13$ & 1.2 \\
\hline Ni_LS1 & 0.01405 & 4.22E-17 & 1.8 & $2.05 \mathrm{E}-14$ & 1.8 \\
\hline Ni_LS6 & 0.00945 & 4.14E-17 & 2 & $2.01 \mathrm{E}-14$ & 2.0 \\
\hline Ni_LS11 & 0.01143 & $3.75 \mathrm{E}-17$ & 2 & $1.83 \mathrm{E}-14$ & 2.0 \\
\hline $\mathrm{Ni}$ LS16 & 0.01023 & $3.75 \mathrm{E}-17$ & 2 & $1.82 \mathrm{E}-14$ & 2.0 \\
\hline Ni_LS21 & 0.01310 & 4.22E-17 & 1.8 & $2.05 \mathrm{E}-14$ & 1.8 \\
\hline Ni_LS26 & 0.01382 & $4.39 \mathrm{E}-17$ & 1.8 & $2.14 \mathrm{E}-14$ & 1.8 \\
\hline Ni_LS31 & 0.01563 & $5.5 \mathrm{E}-17$ & 1.7 & $2.67 \mathrm{E}-14$ & 1.7 \\
\hline Ni_LS36 & 0.00913 & $5.31 \mathrm{E}-17$ & 1.9 & $2.58 \mathrm{E}-14$ & 1.9 \\
\hline
\end{tabular}

used. The uncertainties correspond to one standard deviation and consist of the statistical uncertainty of the gamma spectroscopic measurement together with uncertainties in the efficiency calibration. The uncertainty in the irradiation time is taken into account in the uncertainties of the reaction rates.

\subsection{Efficiency of the Track-length Estimators}

The efficiency of the new track-length estimators in Serpent was studied by comparing the Figures-ofMerit (FOM) to calculations with collision estimators, i.e. the normal way of calculating reaction rates in Serpent. Figure-of-Merit is a good measure for the true performance of a Monte Carlo code in the calculation of different estimators. It is defined

$$
F O M=1 /\left(\sigma^{2} T\right),
$$

where $\sigma$ is the standard deviation of an estimator and $T$ is the transport calculation time. Since $\sigma$ is inversely proportional to the square root of $T$, the FOM is independent of the calculation time. Figuresof-merit for four representative estimators are provided in Table 2.

In the results it can be seen that the reaction rates calculated using collision and track-length estimators agree within statistical deviation, which indicates that the new implementation of the tracklength estimators is working correctly. The usage of the track-length estimators slows down the calculation by about $2 \%$, but on the other hand the statistical deviations of the track-length estimators are significantly smaller than those of the collision estimators. The overall effect is that the figuresof-merit are about 7-8 times higher when using track-length estimators, which means that with the newly implemented feature it is possible to decrease the total calculation times in the current dosimetry calculations by a factor of $7-8$.

Because of the significant difference in the estimator performances, all the reaction rates are calculated using track-length estimators in the following. 
Table 2. Comparison of track-length (T-L) and collision (COL) estimators. The relative uncertainties correspond to one standard deviation, $\sigma$.

\begin{tabular}{|c|c|c|c|c|c|}
\hline & $\begin{array}{c}\text { Calculation } \\
\text { time } \\
\text { (h) }\end{array}$ & $\begin{array}{c}\text { Reaction rate, } \\
\text { CT } \\
(1 / \mathbf{s}) \\
\end{array}$ & $\begin{array}{c}\text { FOM, CT } \\
(1 / \mathbf{s}) \\
\end{array}$ & $\begin{array}{c}\text { Reaction rate, } \\
\text { LS1 } \\
(1 / \mathbf{s}) \\
\end{array}$ & $\begin{array}{c}\text { FOM, LS1 } \\
(1 / \mathrm{s}) \\
\end{array}$ \\
\hline $\mathrm{Mn}, \mathrm{COL}$ & 13.9 & $\begin{array}{c}7.37 \mathrm{E}-11 \\
\pm 0.010\end{array}$ & $0.20 / 1.0$ & $\begin{array}{c}1.71 \mathrm{E}-11 \\
\pm 0.021\end{array}$ & $0.045 / 1.0$ \\
\hline Mn, T-L & 14.1 & $\begin{array}{c}7.38 \mathrm{E}-11 \\
\pm 0.004\end{array}$ & $1.39 / 6.8$ & $\begin{array}{c}1.73 \mathrm{E}-11 \\
\pm 0.007\end{array}$ & $0.378 / 8.3$ \\
\hline $\mathrm{Ni}, \mathrm{COL}$ & 13.7 & $\begin{array}{c}4.28 \mathrm{E}-13 \\
\pm 0.021\end{array}$ & $0.05 / 1.0$ & $\begin{array}{c}2.13 \mathrm{E}-14 \\
\pm 0.095\end{array}$ & $0.002 / 1.0$ \\
\hline $\mathrm{Ni}, \mathrm{T}-\mathrm{L}$ & 14.0 & $\begin{array}{l}4.32 \mathrm{E}-13 \\
\pm 0.007\end{array}$ & $0.36 / 7.8$ & $\begin{array}{c}2.05 \mathrm{E}-14 \\
\pm 0.034\end{array}$ & $0.017 / 7.5$ \\
\hline
\end{tabular}

\subsection{Comparison Between the Measurements and the Calculations}

When comparing the measured reaction rates to the predictions of the original Serpent model, the differences were below $10 \%$ for most of the dosimeters, but for some of them the differences were as high as $30 \%$, which was considered an unacceptable level of error. With the help of the new data, the Serpent model was revised by making the following updates in the model:

- In the original model, the radius of the neutron beam tubes was erroneously $8.4 \mathrm{~cm}$, which was reduced to the correct value $7.6 \mathrm{~cm}$ in the revised model.

- The level of detail in the central thimble was significantly increased by explicitly modelling the air within the irradiation capsule and the bismuth weight on top of the capsule. In the original model the whole irradiation position was coarsely approximated as water-filled.

- The neutron source was modelled as a graphite rod instead of water.

- The air-filled irradiation tube of the pneumatic system was explicitly modelled instead of approximating it as water.

- The beam port plug of the beam tube penetrating the graphite reflector was explicitly modelled.

The results of the Serpent calculations with the revised model and a comparison to the measurements are provided in Table 3. In addition, the thermal power distribution is shown in Fig. 3, and the reaction rates in the irradiation ring for $\mathrm{Mn}$ and $\mathrm{Ni}$ are depicted in Fig. 4. The calculated multiplication factors are $0.99966 \pm 6 \mathrm{pcm}$ and $1.00091 \pm 6 \mathrm{pcm}$ for the manganese and nickel irradiations, respectively. Even after the revisions in the model, up to $20 \%$ errors exist in the manganese and $17 \%$ in the nickel reaction rates.

\section{Summary and Conclusions}

In the current study, the Serpent model of the Triga Mk-II research reactor was validated by measuring the nickel and manganese reaction rates at 9 different positions within the reactor and by comparing the results to estimations of the model. The Serpent model also somewhat revised, since the modelling of the neutron dosimeters revealed some flaws and inaccuracies in the original model. In addition, track-length estimators were implemented in Serpent 2.1.18 as an alternative for the standard collision estimators.

The newly implemented track-length estimation capability increased the performance of reaction rate estimators significantly compared to the standard approach of Serpent. When using the new implementation of the track-length estimators, the calculation time per transported neutron increases by a few percent, but at the same time the deviations of the reaction rate estimators decrease such that a certain level of statistical accuracy can be reached using only about 1/8-1/7 of the CPU time that would be required with collision estimators. 


\section{$15^{\text {th }}$ ISRD}

Table 3. Comparison of calculated and measured reaction rates.

\begin{tabular}{|l|c|c|c|c|}
\hline & $\begin{array}{c}\text { Calculated } \\
(\mathbf{1} / \mathbf{s})\end{array}$ & $\begin{array}{c}\text { Measured } \\
\mathbf{( 1 / s )}\end{array}$ & Difference (\%) & $\begin{array}{c}\text { Std. Dev. Of } \\
\text { difference (\%) }\end{array}$ \\
\hline Mn_CT & $7.38 \mathrm{E}-11$ & $8.13 \mathrm{E}-11$ & -9 & 2.7 \\
Mn_LS_1 & $1.73 \mathrm{E}-11$ & $1.51 \mathrm{E}-11$ & 14 & 2.9 \\
Mn_LS_6 & $1.53 \mathrm{E}-11$ & $1.38 \mathrm{E}-11$ & 11 & 3.0 \\
Mn_LS_11 & $1.56 \mathrm{E}-11$ & $1.47 \mathrm{E}-11$ & 6 & 3.0 \\
Mn_LS_16 & $1.56 \mathrm{E}-11$ & $1.31 \mathrm{E}-11$ & 20 & 3.0 \\
Mn_LS_21 & $1.61 \mathrm{E}-11$ & $1.59 \mathrm{E}-11$ & 1 & 3.0 \\
Mn_LS_26 & $1.33 \mathrm{E}-11$ & $1.49 \mathrm{E}-11$ & -11 & 3.0 \\
Mn_LS_31 & $1.08 \mathrm{E}-11$ & $1.10 \mathrm{E}-11$ & -2 & 3.3 \\
Mn_LS_36 & $1.43 \mathrm{E}-11$ & $1.24 \mathrm{E}-11$ & 15 & 3.2 \\
\hline Ni_CT & $4.32 \mathrm{E}-13$ & $4.78 \mathrm{E}-13$ & -10 & 1.4 \\
Ni_LS_1 & $2.05 \mathrm{E}-14$ & $2.05 \mathrm{E}-14$ & 0 & 3.9 \\
Ni_LS_6 & $2.35 \mathrm{E}-14$ & $2.01 \mathrm{E}-14$ & 17 & 3.7 \\
Ni_LS_11 & $1.88 \mathrm{E}-14$ & $1.83 \mathrm{E}-14$ & 3 & 4.0 \\
Ni_LS_16 & $1.73 \mathrm{E}-14$ & $1.82 \mathrm{E}-14$ & -5 & 4.2 \\
Ni_LS_21 & $1.82 \mathrm{E}-14$ & $2.05 \mathrm{E}-14$ & -11 & 4.0 \\
Ni_LS_26 & $2.23 \mathrm{E}-14$ & $2.14 \mathrm{E}-14$ & 4 & 3.7 \\
Ni_LS_31 & $2.89 \mathrm{E}-14$ & $2.67 \mathrm{E}-14$ & 8 & 3.4 \\
Ni_LS_36 & $2.43 \mathrm{E}-14$ & $2.58 \mathrm{E}-14$ & -6 & 3.7 \\
\hline
\end{tabular}

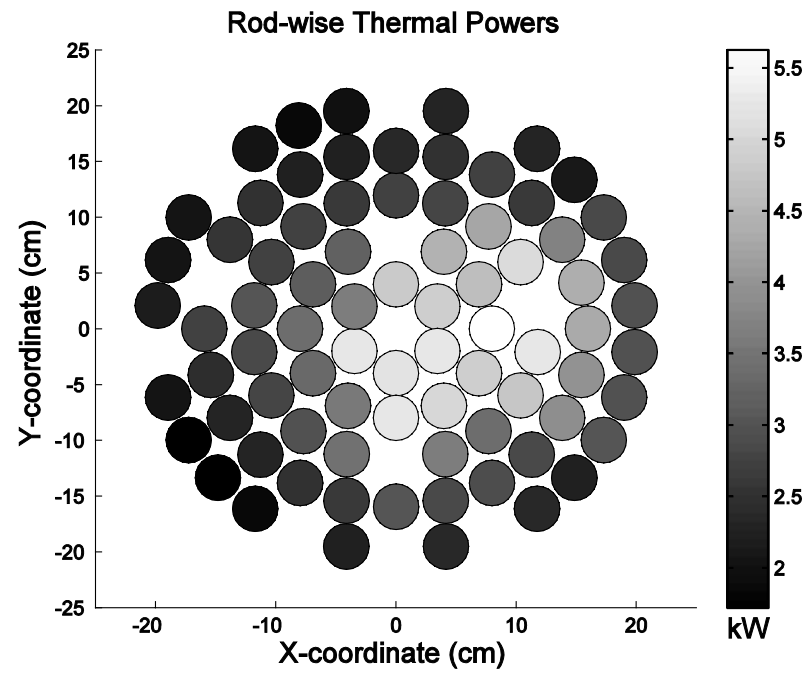

Figure 3. The calculated thermal power distribution in the core with control rod positions corresponding to the Mn irradiation. The effect of the asymmetric fuel loading can be seen in the power distribution, which is tilted in the direction of the positive $\mathrm{x}$-axis.

The predictions of the Serpent calculation model were in a satisfactory, but not perfect agreement with the measurements. The model under-predicted the reaction rates of both the dosimeter materials in the central thimble by about $10 \%$. Reason for this may be related to the fact that the location of these samples is not known very accurately. Thus, the modelled location of the sample may be off by a couple of centimetres in the axial direction, and the corresponding spatial variation in the neutron flux might explain the error in the calculated reaction rates.

The $-15-+20 \%$ differences in the reaction rates at the Lazy Susan Irradiation ring are accounted for the general inaccuracy of the model, including for example coarse division of the material zones in the burnup calculation, together with uncertainties in the history model of the burnup calculation and cross 

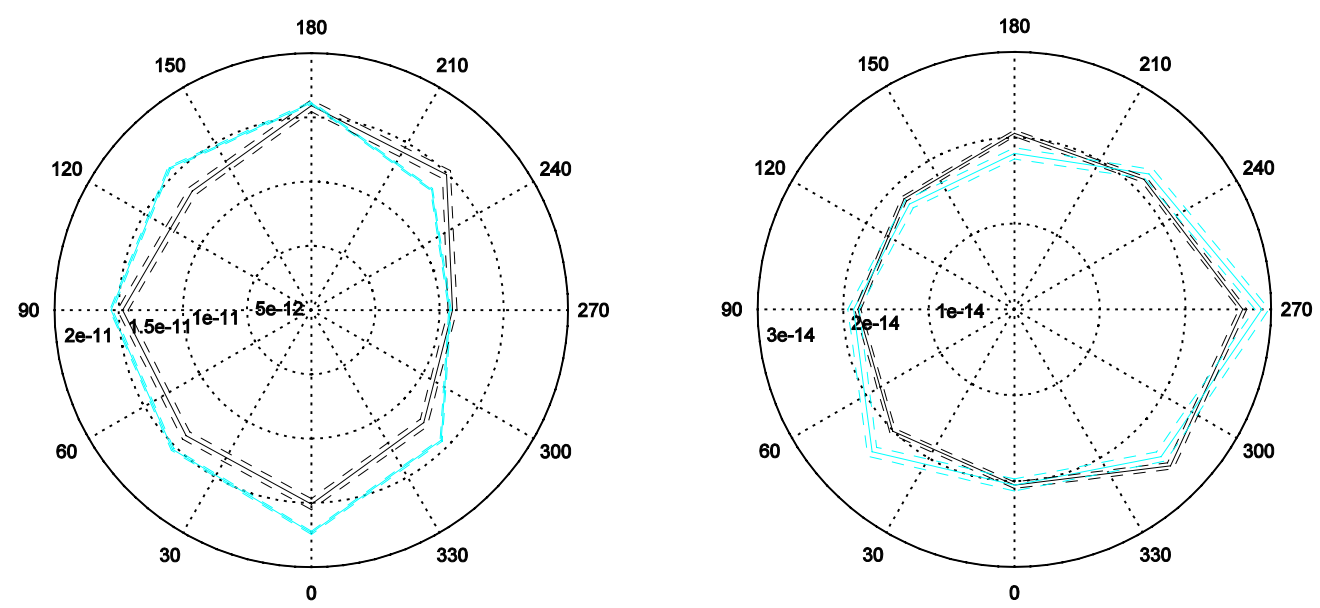

Figure 4. Calculated (grey) and measured (black) reaction rates for Mn (left) and Ni (right) in the Lazy Susan irradiation ring. The position number 1 is located at 0 degrees, number 6 is at 45 degrees etc. The dashed lines represent the standard deviations of the results and the unit of the reaction rates is $\mathrm{s}^{-1}$.

section data. However, the results show that the power calibration of the reactor seems to be in rather good agreement with the normalization of the Serpent model, since no clear positive or negative bias can be recognized in the estimated reaction rates. In addition, the fact that the nickel reaction rates within the irradiation ring are in quite good agreement indicate that the calculated fission power distribution within the reactor is rather accurate. Hence, the lack of thermal hydraulics feedback in the model might not be a problem at all. Nevertheless, more comparisons with experimental data are needed to confirm this observation.

In the future, it would be compare the flux distributions also in the axial direction. Also repeating the burnup calculation with the revised model of the reactor would increase the accuracy of the fuel inventories and the model as a whole.

\section{References}

[1] Serpent Website http://montecarlo.vtt.fi [referenced 24.3.2014]

[2] J. Leppänen, "Development of a new Monte Carlo reactor physics code." D.Sc. Thesis, Helsinki University of Technology (2007)

[3] T. Viitanen and A. Räty, “Calculating the nuclide inventory of FiR 1 TRIGA Mk-II reactor”, VTT Reports, VTT-R-05511-12 (2012, unpublished)

[4] I. Auterinen et al., "Metamorphosis of a 35 year-old triga reactor into a modern BNCT facility", Frontiers in Neutron Capture Therapy, 1, Kluwer Academic / Plenum Publishers, New York, 67-275 (2001)

[5] A. Santamarina et al. "The JEFF-3.1.1 Nuclear Data Library", OECD/NEA, ISBN 978-92-6499074-6 (2009)

[6] International Atomic Energy Agency, "International Reactor Dosimetry File 2002 (IRDF-2002)", STI/DOC/010/452, ISBN 92-0-105106-9, (2006) 